\title{
In-Silico study of Some Natural Plant Phyto-compounds for the Identification of Novel potent Cholinesterase Inhibitors Against Alzheimer Disease
}

\author{
Dhiraj Kumar a and Sanjana Bhagat ${ }^{\text {a }}$ \\ a Department of pharmaceutical Sciences of Technology, Birla Institute of Technology, Mesra, \\ Ranchi, India
}

\begin{abstract}
:
The main aim of this study is to identify inhibitory binding potent of the available commercially alkaloids, against the crystal structure of acetylcholinesterase (AChE) protein by in silico studies. The inhibitory data of the compounds should be compared with the internal ligand as well as standard AChE inhibitor Aricept (which is used for the treatment of all stages of Alzheimer's disease). AutoDock 4.0 is used for the docking study, conformational orientation site analysis, and, with the help of docking, we have calculated parameters like binding energy and inhibition constant. Docking's study showed that Glabridin, Isorosmanol, Quercetin, Honokiol, Eckol, Sargaquinoic acid, and Ginsedosides revealed strong binding affinity with the enzyme. Moreover, The ADMET profiling and physicochemical properties of the selected compounds are evaluated using the Molinspiration and Data warrior software. By showing a strong binding affinity value, positive bioactivity score, and good pharmacokinetic properties, the top compound was determined. After evaluation with all parameters, the compound Glabridin and Ginsedosides show the most potent inhibitory effect towards the acetylcholinesterase, so this compound could be used as a novel is required to treat Alzheimer's disease.
\end{abstract}

Keywords: Phytocompounds, Binding energy, ADMET, Molecular docking 


\section{Introduction}

Alzheimer's disease is the most prevalent progressive neurodegenerative condition, which is considered by low concentration amount of neurotransmitter (acetylcholine), oxidative stress, and neuroinflammatory are all symptoms of Alzheimer's disease (AD) ${ }^{1}$. Most effective treatment methods focus on activating the cholinergic receptors in the brain to improve cholinergic function, increase the concentration level of acetylcholine (Ach), to avoid breakdown by cholinesterase enzyme and other inflammatory agents ${ }^{2}$.

$\mathrm{ACh}$ is the main neurotransmitter present in the central nervous systems, autonomic ganglia, different organs with the autonomic transmission, the neuromuscular junction, and synapses, ach is predominantly found in between two neurons, and have also found in the vital long-axon part of cholinergic pathways. One of the pathologies linked to Alzheimer's disease is the degeneration of this system ${ }^{3}$. During the neurotransmission process, ach is come from the nerve into the synaptic cleft part of the neuro-junction and binds to the Ach receptors (nicotinic and muscarine) present on the post-synaptic membrane, transmit the signal from the nerve. Acetylcholinesterase (AChE), is also found on the post-synaptic membrane, which blocks the signal transmission by hydrolysis of $\mathrm{Ach}^{4}$. AChE is present in the different types of conducting tissue such as nerve and muscle, sensory and motor fibers, peripheral and central tissue, and cholinergic and noncholinergic fibers. AChE is more active in motor neurons compared to sensory neurons 5-6. Pseudocholinesterase is also called plasma cholinesterase or butyrylcholinesterase, is present in the liver. Different forms of cholinesterase ie. Ach and BuChE hydrolyze butyrylcholine is more rapid than Ach ${ }^{7}$. AChE enzyme hydrolysis the ester bond present in acetylcholine breaks into choline and ester. In Alzheimer Disease increase the concentration of $\mathrm{AChE}$ and BuChE outcomes into the decreased half-life of Ach ${ }^{8}$.

In currently for the treatment and slowing down of $\mathrm{AD}$ is most favorable target is cholinesterase inhibitors ${ }^{9}$. Cholinergic neurons are mainly found in that region which is associated with learning and memory - spread out from basal forebrain 10. By inhibition of the acetylcholinesterase (AChE), breakdowns of Ach are decreased, thus progress the learning and memory purpose.

Alkaloids, terpenoids, Shikimate-derived chemicals, and other chemicals that are antibacterial, antiviral, antioxidant, anti-inflammatory, and enzyme inhibition are among the biological and pharmacological actions of this category of natural compounds. ${ }^{\mathbf{1 1 , 1 2}}$. Alkaloids can be a capable phytoconstituent for the treatment of $\mathrm{AD}$ by inhibition of $\mathrm{AChE}$, so it can increase the level of 
Ach. Hence, our aim of the present analysis is to find out the AChE affinity potential of certain commercially available alkaloids and terpenoids by comparing the drug Aricept which is already used for $\mathrm{AD}$ by using in silico studies. Figure 1 represents the main crucial Phytochemicals present in plants usage for AD.

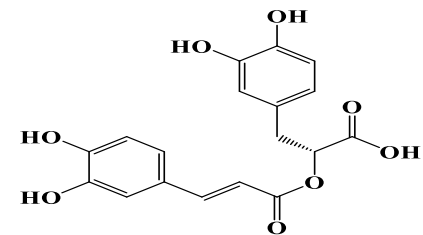

Rosmarinic acid

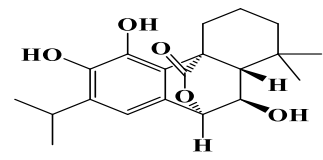

Isorosmanol

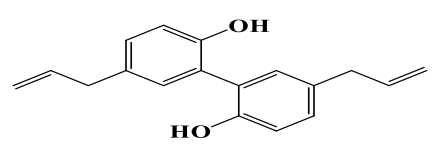

Magnolol
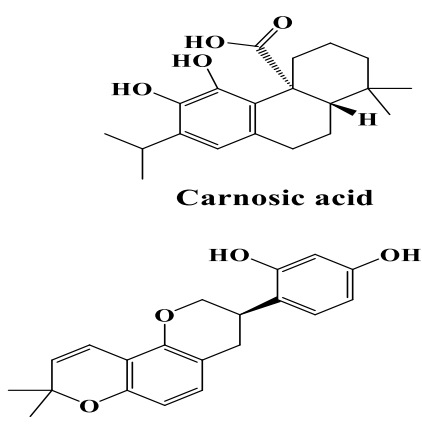

Glabridin<smiles>Cc1cc(O)c2c(=O)c(O)c(C3CCC(O)C(C)C3)oc2c1</smiles>

Quercetin

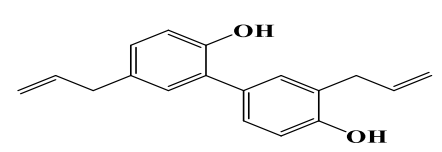

Honokiol<smiles>Oc1cc(O)cc(Oc2c(O)cc(O)c(Oc3cc(O)cc(O)c3)c2Oc2cc(O)cc(O)c2)c1</smiles>

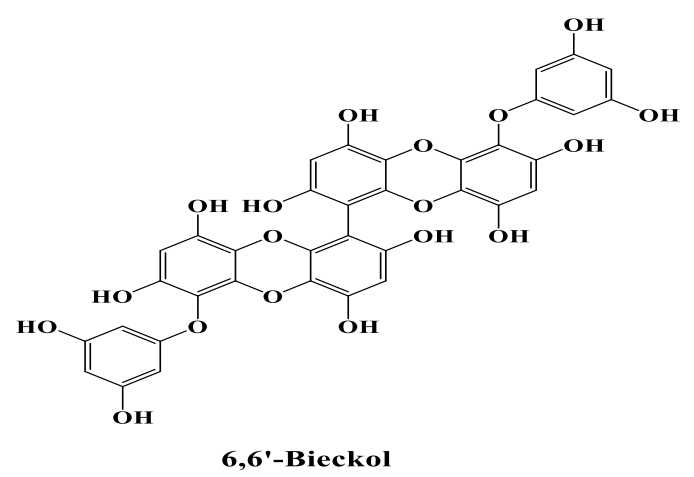


<smiles></smiles><smiles>CCCCC/C=C/C(=O)CCc1ccc(O)c(OC)c1</smiles>

(6)-Shogaol

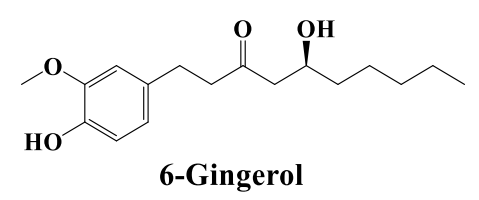<smiles>CCCCCCCCC[C@H](O)C(OC)C(=O)CCc1ccc(O)c(OC)c1</smiles>

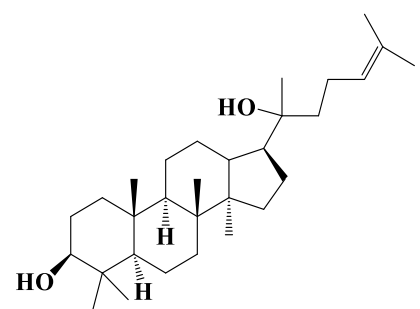

Ginsedosides<smiles></smiles>

Dieckol<smiles>CCCCCCCC/C=C/C(=O)CCc1ccc(O)c(OC)c1</smiles>

(8)-Shogaol<smiles>CCCCCCCCC[C@H](O)CC(=O)CCc1ccc(O)c(OC)c1OC</smiles>

Methoxy-[6]-gingerol<smiles>O=C(O)c1cc(O)c(O)c(O)c1</smiles>

Gallic acid

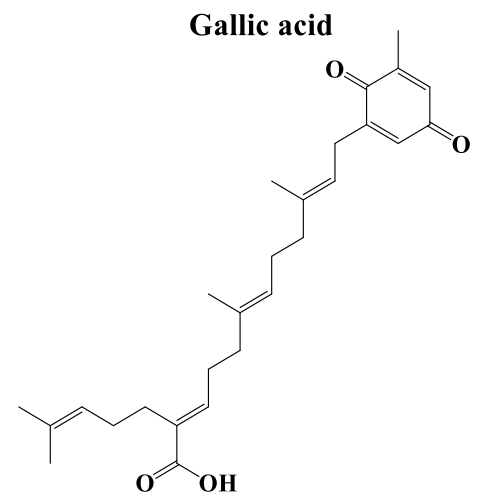

Sargaquinoic acid

Fig 1: Structure of Phytochemicals used for AD 


\section{Materials and Methods:}

\section{Workflow}

This diagram (Figure 2) shows the following steps: (a) the natural alkaloids, terpenoids, Aricept and cholinesterase inhibitors protein preparation, (b) molecular docking method, (c) ADMET Predication.

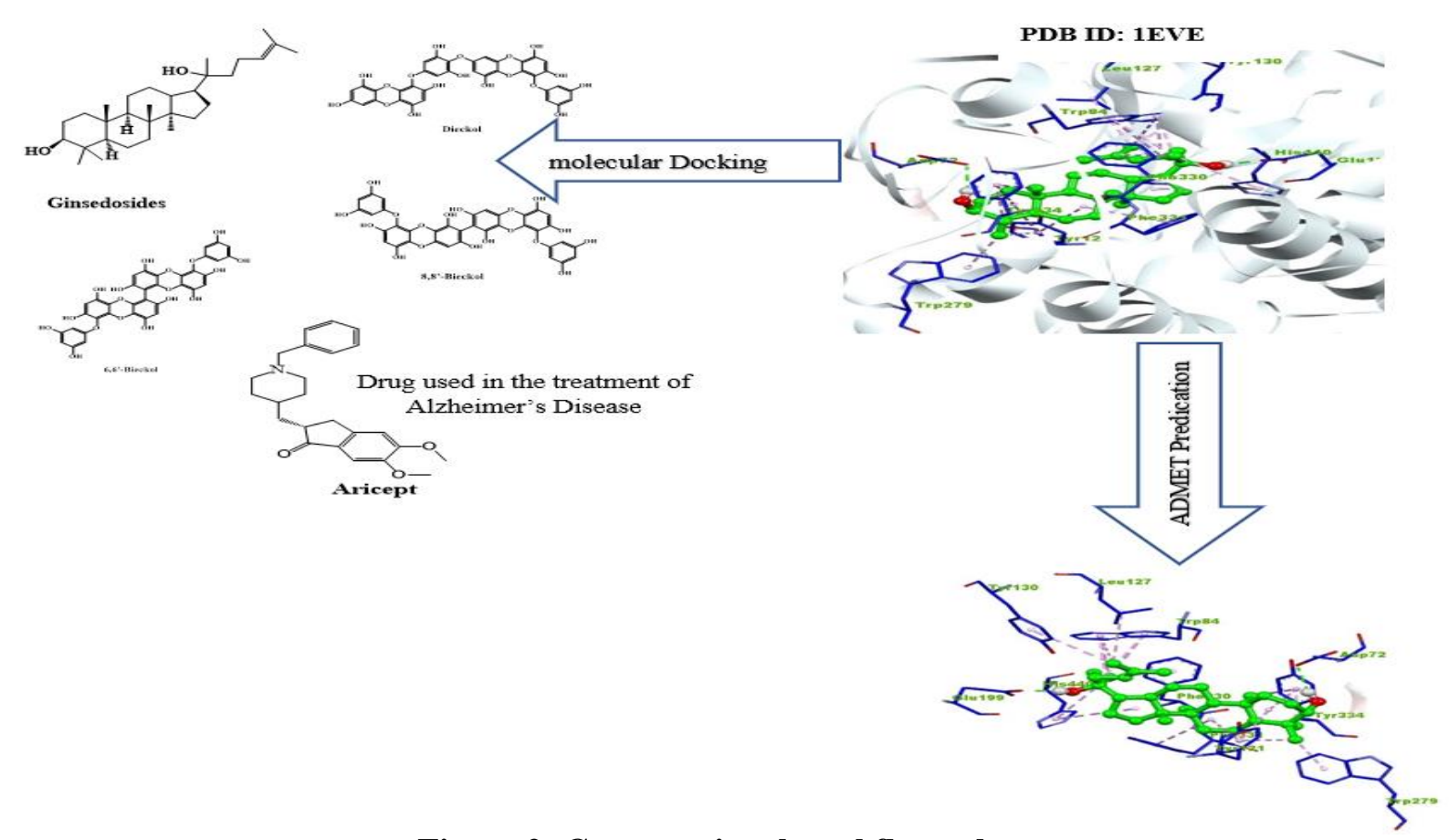

Figure 2: Computational workflow scheme

\section{Software used}

By using Molecular graphics laboratory (MGL) tools and Auto dock 4.0 was downloaded from (www.scripps.edu) ${ }^{13}$, 'Discovery studio visualizer' was downloaded from (https://discover.3ds.com/discovery-studio-visualizer-download) ${ }^{\mathbf{1 4}}$, Chemdraw 2d \& $3 \mathrm{~d}$ (https://www.perkinelmer.com/), Molinspiration (http://www.molinspiration.com/) and Bioinformatics software Osiris Data Warrior (http://www.openmolecules.org/data).

\section{Preparation of ligand and molecular target selection:}

Nineteen potent compounds, alkaloids, and terpenoids were selected from the pub med literature, which showed an inhibitory effect on Alzheimer's Disease. The Canonical SMILES structure of the natural compound was downloaded from the Pub Chem database (http://pubchem.ncbi.nlm.nih.gov/). The acetylcholinesterase enzyme, which has PDB Id (1EVE), was selected for our study. The crystal structure of the acetylcholinesterase target was downloaded from the Protein Data Bank (http://www.rcsb.org/ PDB/home/home.do). 


\section{Molecular Docking}

The molecular docking process between the co-crystallized molecules and the receptor target acetylcholinesterase (PDB 1EVE) was performed with the help of Auto-dock 4.0 software. During docking simulation ligands and protein were treated as a rigid structure. Each ligand retained ten docking conformer poses were obtained, with the help of a binding energy score to select the best conformer inside the active site of the protein and significant interaction with the key residues of the amino acid. This docking result was compared to the Aricept, (Table 1) which has already satisfactory results in the AD treatment.

\section{Bioactivity Score \& molecular Properties calculation:}

Lipinski's "Rule of 5" attributes are a collection of chemical forms he utilized to create his "Rule of 5." The rule is beneficial during the drug development process. Molecular mass, lipophilicity, hydrogen bond acceptors, hydrogen bond donors, and bioactivity score.

\section{In-silico Toxicity Potential Assessment:}

In the early stages of drug development, determining the ADME and toxicity report of various characteristics of Phyto-compounds is critical. All of the ligands' toxic parameters were examined. Toxicity testing covers mutagenic, carcinogenic, and skin irritant screening.

\section{Results and Discussions}

\section{Molecular Docking Analysis}

The natural alkaloids and terpenoids are Glabridin, Isorosmanol, Quercetin, Honokiol, Eckol, Sargaquinoic acid, and Ginsenosides, which are generally found in various types of medicinal and dietary sources, comprise several pharmacophoric characteristics which are applicable as a drug-like moiety. Orientation of these compounds overlaps the native E2020 ligand (ARICEPT) has shown significant overlaps and similarities in binding orientation and interaction (Figure 3). Hence these similarities have cleared that all seven phytocompounds can act as potent inhibitors of acetylcholinesterase. 


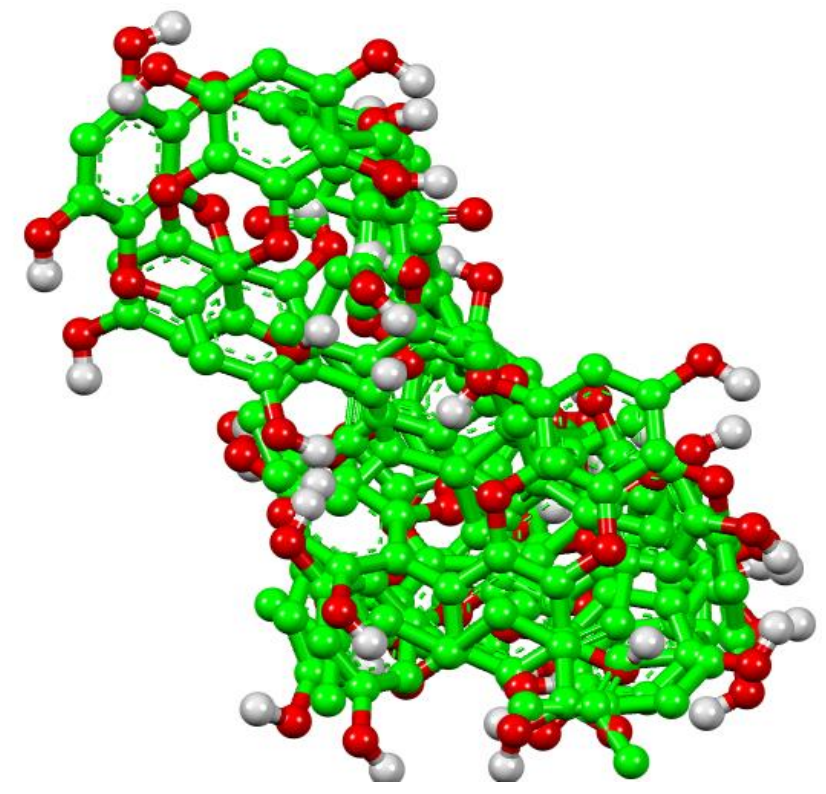

(a)

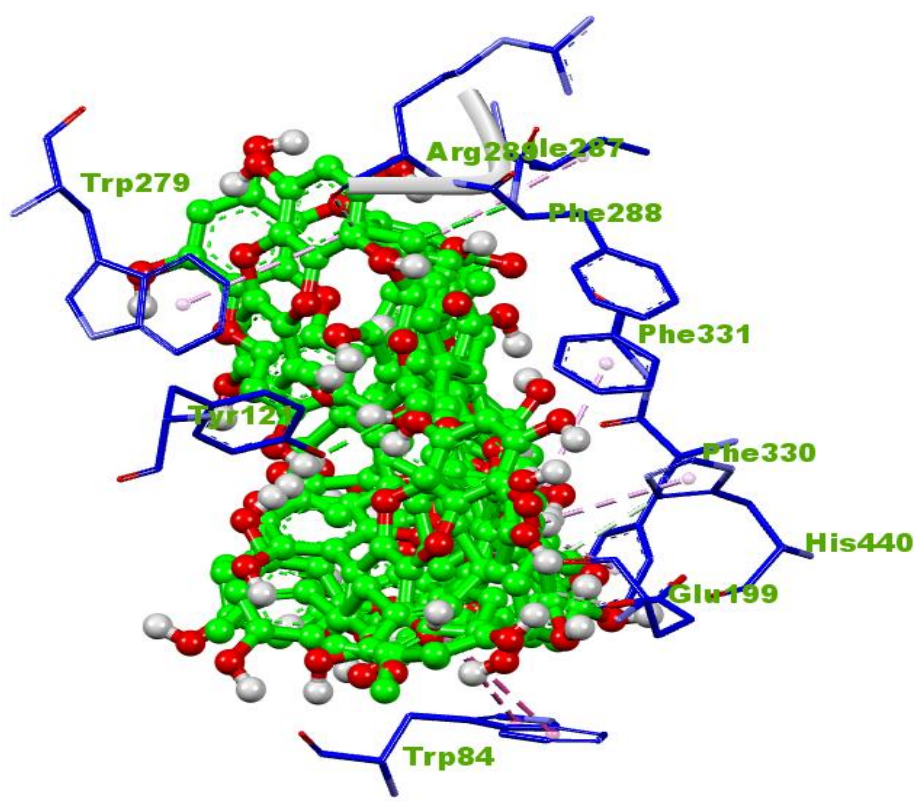

(c)

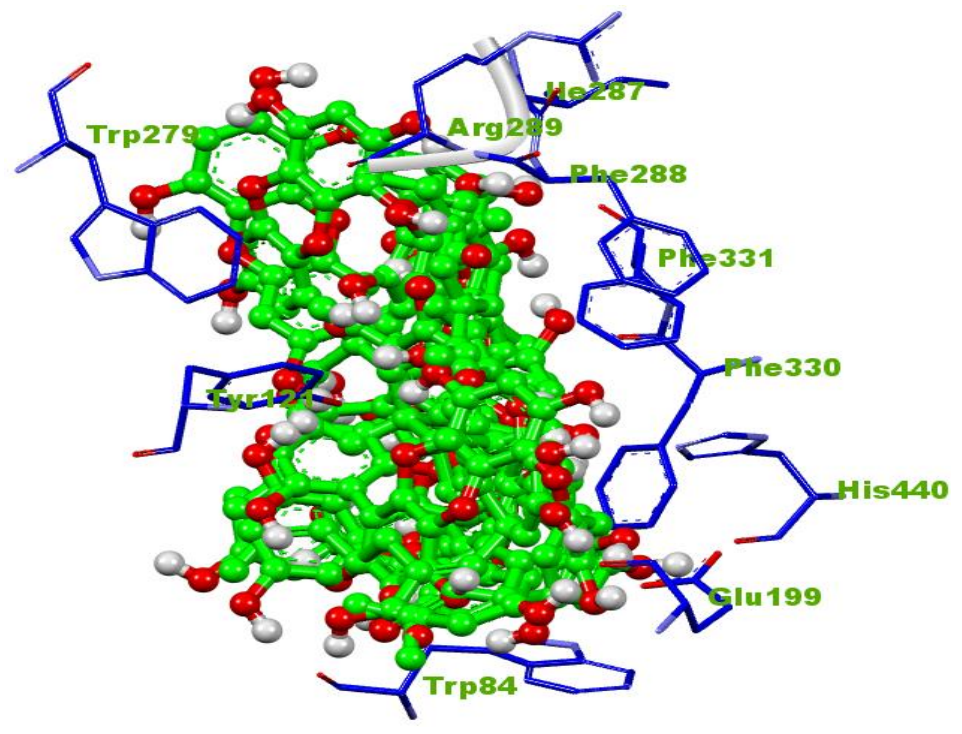

(b)

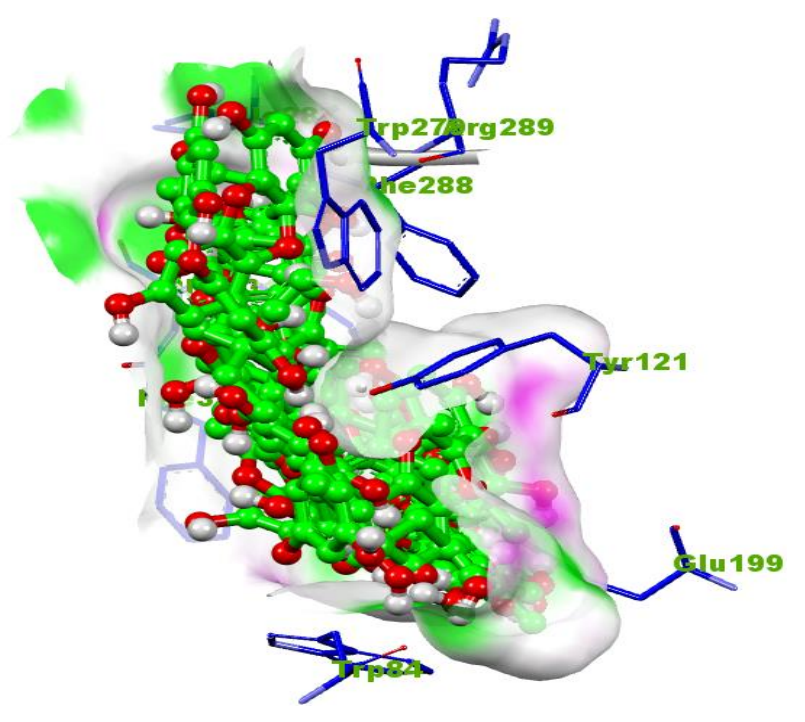

(d)

Figure 3. Different views of the docked protein-ligand complex. (a) Alkaloids and structure get superposition (b) binding orientation of the structure of ligands in the 1EVE active site (c) significant different type of interaction recognized by the ligands with the residue of 1EVE active site (d) the donor and acceptor hydrogen surfaces around the ligand. 
The molecular docking of these phytocompounds in the active site of acetylcholinesterase receptors gave a negative binding score of $-11.15,-9.94,-9.33,-9.34,-9.87,-9.49$, and -13.38 for Glabridin, Isorosmanol, Quercetin, Honokiol, Eckol, Sargaquinoic acid, and Ginsedosides, respectively, which has significantly close to the binding score of Aricept, - 12.15. these compounds bind into the $1 \mathrm{EVE}$ active site have displayed effective Interaction and formation of hydrogen bonds with TRP279, ARG289, TYR121, GLU129, residues (Figure 4). However, different type of interaction, such as van der Waals, п-п stacked, and water hydrogen bonds has stimulated the binding orientation and stack of these ligands with the active site residues, supported our study to a much greater scope. Glabridin and Ginsedosides have additional п-п stacked interactions with TYR7. Out of seven ligands, these four are displayed the highest number of interactions with the highest amount of amino acid residues.

Hence, TRP279, TRP84, HIS440, PHE331, and ARG289 residues established their important role in various interactions of diverse chemical natures between the ligand and target protein. We can indicate that Glabridin and Ginsedosides most capable drug molecules required to diagnose Alzheimer's condition.

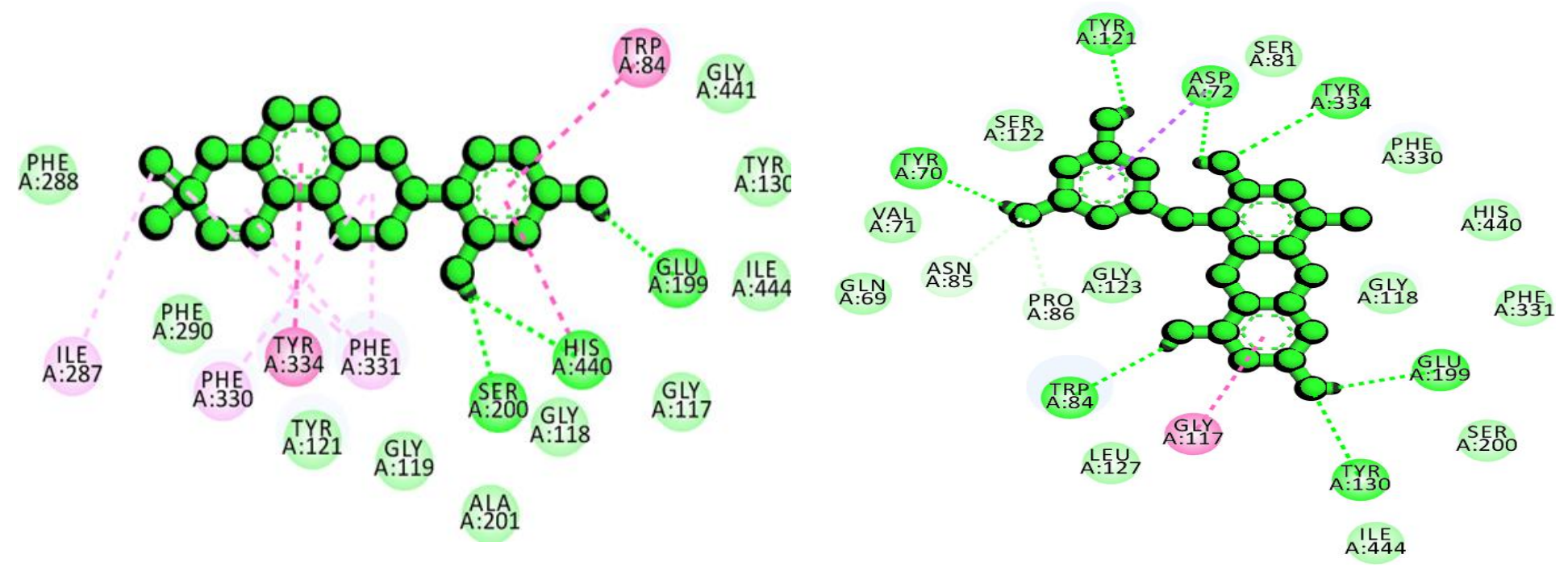




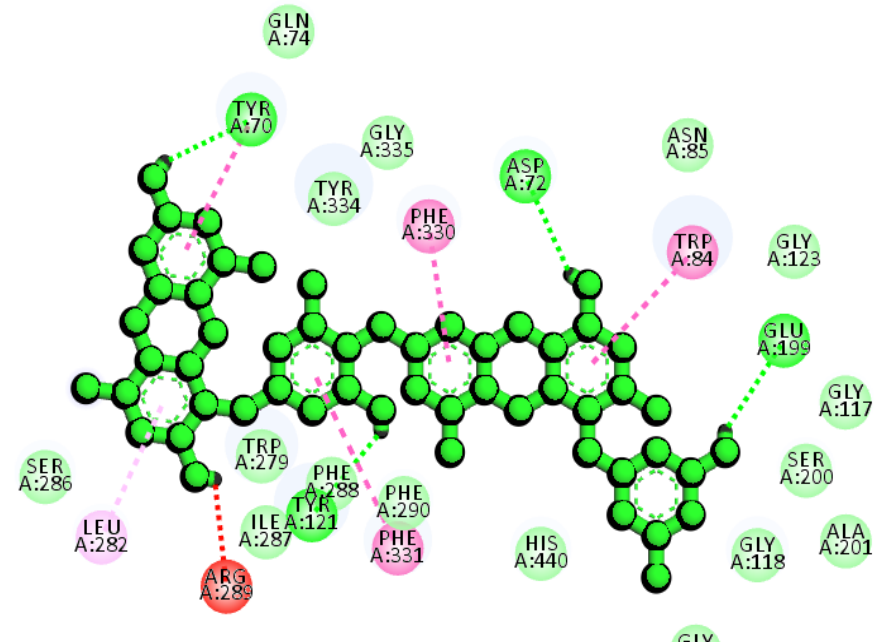

A. G:19

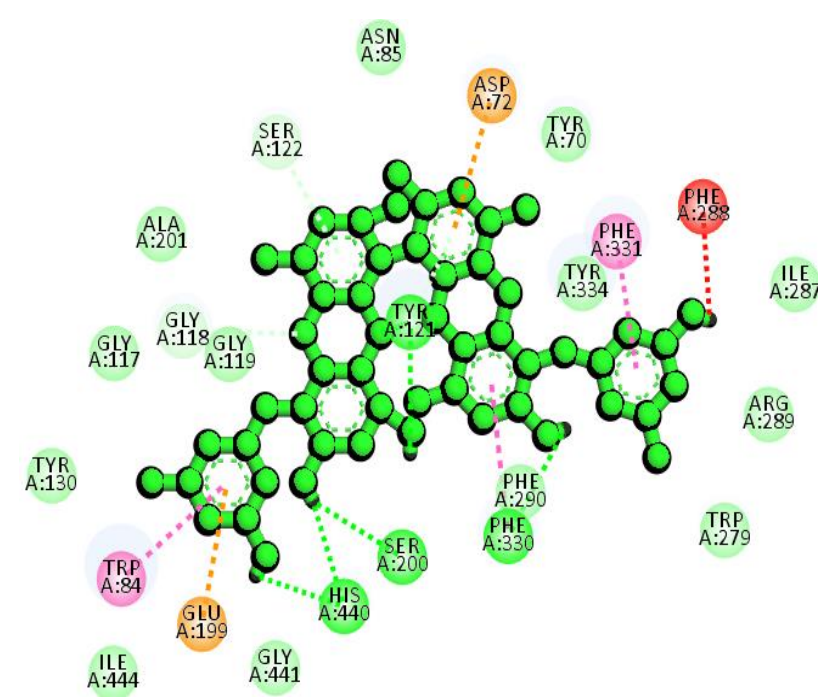

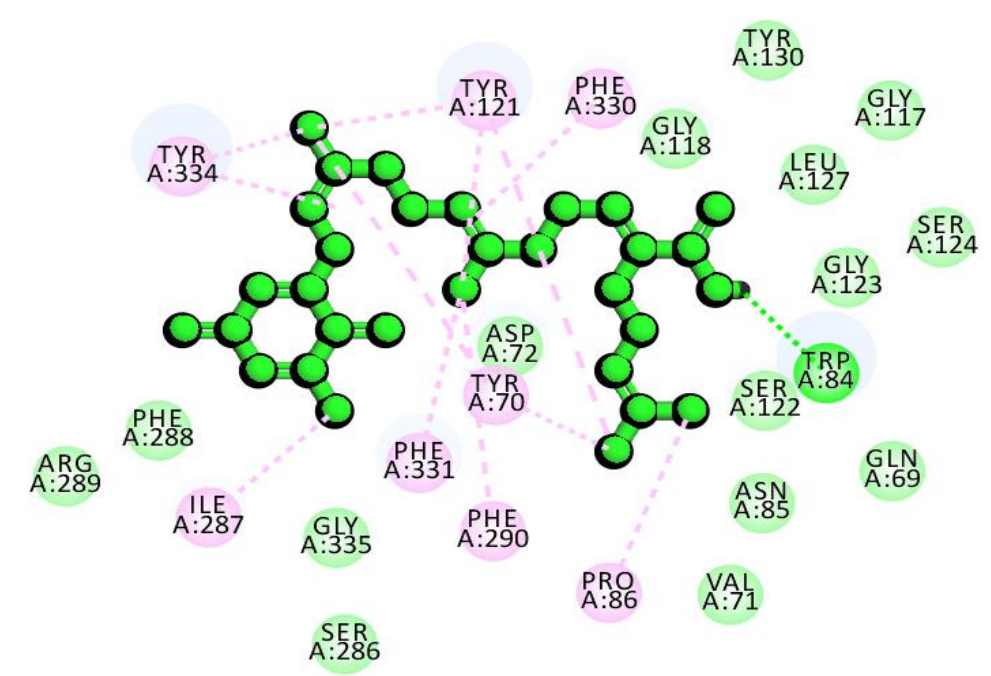

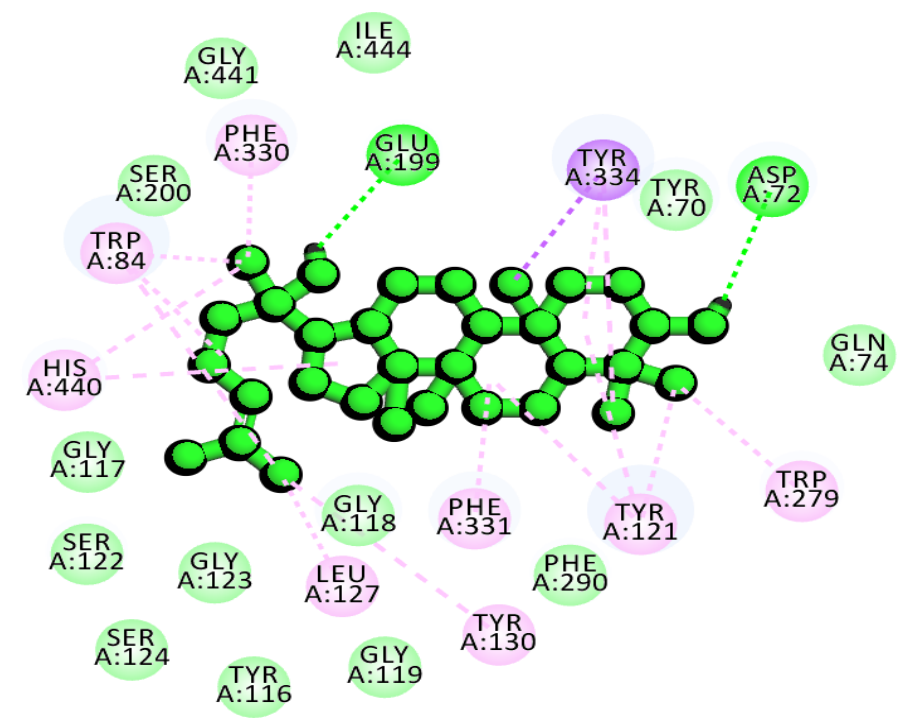

Figure 4. 2D representation of amino acid interaction between natural ligands, and co-crystallized (Aricept) in the binding site of $1 \mathrm{EVE}$. 


\begin{tabular}{|c|c|c|c|c|}
\hline S. no. & $\begin{array}{c}\text { Name of } \\
\text { Compound } \\
\end{array}$ & $\begin{array}{l}\text { Molecular } \\
\text { Formula }\end{array}$ & Binding Affinity (Kcal/mol) & Inhibition Constant(kI) \\
\hline 1 & Rosmarinic acid & $\mathrm{C}_{18} \mathrm{H}_{16} \mathrm{O}_{8}$ & -7.6 & $2.68 \mathrm{uM}$ \\
\hline 2 & Carnosic acid & $\mathrm{C}_{20} \mathrm{H}_{28} \mathrm{O}_{4}$ & -9.01 & $249.11 \mathrm{nM}$ \\
\hline 3 & Quercetin & $\mathrm{C}_{15} \mathrm{H}_{10} \mathrm{O}_{7}$ & -9.33 & $145.9 \mathrm{nM}$ \\
\hline 4 & Isorosmanol & $\mathrm{C}_{20} \mathrm{H}_{26} \mathrm{O}_{5}$ & -9.94 & $52.03 \mathrm{nM}$ \\
\hline 5 & Glabridin & $\mathrm{C}_{20} \mathrm{H}_{20} \mathrm{O}_{4}$ & -11.15 & $6.72 \mathrm{nM}$ \\
\hline 6 & Honokiol & $\mathrm{C}_{18} \mathrm{H}_{18} \mathrm{O}_{2}$ & -9.34 & $142.88 \mathrm{nM}$ \\
\hline 7 & Magnolol & & -8.89 & $303.85 \mathrm{nM}$ \\
\hline 8 & Eckol & $\mathrm{C}_{18} \mathrm{H}_{12} \mathrm{O}_{9}$ & -9.87 & $58.53 \mathrm{nM}$ \\
\hline 9 & 6,6'-Bieckol & $\mathrm{C}_{42} \mathrm{H}_{26} \mathrm{O}_{21}$ & -12.07 & $1.41 \mathrm{nM}$ \\
\hline 10 & 8,8'-Bieckol & $\mathrm{C}_{36} \mathrm{H}_{22} \mathrm{O}_{18}$ & -11.64 & $2.92 \mathrm{nM}$ \\
\hline 11 & Dieckol & $\mathrm{C}_{36} \mathrm{H}_{22} \mathrm{O}_{18}$ & -13.75 & $82.71 \mathrm{pM}$ \\
\hline 12 & (6)-Shogaol & $\mathrm{C}_{17} \mathrm{H}_{24} \mathrm{O}_{3}$ & -8.16 & $1.04 \mathrm{uM}$ \\
\hline 13 & (8)-Shogaol & $\mathrm{C}_{19} \mathrm{H}_{28} \mathrm{O}_{3}$ & -8.19 & $985.76 \mathrm{nM}$ \\
\hline 14 & 6-Gingerol & $\mathrm{C}_{17} \mathrm{H}_{26} \mathrm{O}_{4}$ & -6.81 & $10.27 \mathrm{uM}$ \\
\hline 15 & $\begin{array}{c}\text { Methoxy-[6]- } \\
\text { gingerol }\end{array}$ & $\mathrm{C}_{22} \mathrm{H}_{36} \mathrm{O}_{5}$ & -8.04 & $1.28 \mathrm{uM}$ \\
\hline 16 & $\begin{array}{l}\text { Methoxy-[10]- } \\
\text { gingerol }\end{array}$ & $\mathrm{C}_{22} \mathrm{H}_{36} \mathrm{O}_{5}$ & -7.61 & $2.65 \mathrm{uM}$ \\
\hline 17 & Gallic acid & $\mathrm{C}_{7} \mathrm{H}_{6} \mathrm{O}_{5}$ & -3.67 & $2.04 \mathrm{mM}$ \\
\hline 18 & Sargaquinoic acid & $\mathrm{C}_{27} \mathrm{H}_{36} \mathrm{O}_{4}$ & -9.49 & $109.71 \mathrm{nM}$ \\
\hline 19 & Ginsedosides & $\mathrm{C}_{30} \mathrm{H}_{52} \mathrm{O}_{2}$ & -13.38 & $154.97 \mathrm{pM}$ \\
\hline
\end{tabular}

TABLE 1: Binding energy of different phytocompounds with Acetylcholinesterase receptor

\section{Bioactivity Score \& Lipinski Properties Calculation:}

For the aim of evaluating the bioactivity score and Lipinski characteristics, nineteen Phytocompounds were selected. The SMILES format was used to upload each natural Phytocompounds into Molinspiration online services. ${ }^{15}$. The cross-ponding molecular properties and bioactivity score were recovered. We observe that all compounds showed not more than one violation of all the five rules of Lipinski. Compounds should have a molecular weight of less than 500, a partition coefficient of less than 5, and many rotatable bonds of less than 10, among other things. the Log P value observed of top leads compounds was found less than five. Results of Lipinski properties of the best virtual compounds were shown in Table 2. By analyzing the result with the help of Molinspiration software, Compounds that follow the "Rule of Five" that fulfill all bioactive characteristics such GPCR ligand, Ion channel modulator, nuclear receptor ligand, protease inhibitor, enzyme inhibitor, and kinase inhibitor were identified ${ }^{\mathbf{1 6}}$. 
The score was used to determine all of these parameters. The maximum activity shows the maximum possibility to be active. These scores were lies between -0.50 to +0.50 then this type of compound should consider for oral drugs. The compound Glabridin was satisfying the Lipinski properties as well as bioactive score are shown in Table 3.

\begin{tabular}{|c|c|c|c|c|c|c|c|c|}
\hline $\begin{array}{l}\text { Compound } \\
\text { Name }\end{array}$ & $\begin{array}{l}\text { Molecular } \\
\text { Formula }\end{array}$ & $\log P$ & TPSA & HBA & HBD & $\begin{array}{c}\text { Number } \\
\text { of } \\
\text { rotatable } \\
\text { bonds }\end{array}$ & $\begin{array}{c}\text { Number } \\
\text { of } \\
\text { violations }\end{array}$ & Volume \\
\hline Glabridin & $\mathrm{C}_{20} \mathrm{H}_{20} \mathrm{O}_{4}$ & 4.20 & 58.92 & 4 & 2 & 1 & 0 & 295.25 \\
\hline Eckol & $\mathrm{C}_{18} \mathrm{H}_{12} \mathrm{O}_{9}$ & 2.56 & 156.88 & 9 & 6 & 2 & 1 & 291.08 \\
\hline Isorosmanol & $\mathrm{C}_{20} \mathrm{H}_{26} \mathrm{O}_{5}$ & 3.70 & 86.99 & 5 & 3 & 1 & 0 & 320.51 \\
\hline Honokiol & $\mathrm{C}_{18} \mathrm{H}_{18} \mathrm{O}_{2}$ & 5.00 & 40.46 & 2 & 2 & 5 & 1 & 260.55 \\
\hline Quercetin & $\mathrm{C}_{15} \mathrm{H}_{10} \mathrm{O}_{7}$ & 1.68 & 131.35 & 7 & 5 & 1 & 0 & 240.08 \\
\hline Sargaquinoic acid & $\mathrm{C}_{27} \mathrm{H}_{36} \mathrm{O}_{4}$ & 6.89 & 71.44 & 4 & 1 & 12 & 1 & 431.68 \\
\hline Ginsenosides & $\mathrm{C}_{30} \mathrm{H}_{52} \mathrm{O}_{2}$ & 8.02 & 40.46 & 2 & 2 & 4 & 1 & 479.88 \\
\hline
\end{tabular}

Table 2: Physicochemical Properties of the best Phyto-compounds

\begin{tabular}{|c|c|c|c|c|c|c|}
\hline Name of ligand & $\begin{array}{c}\text { GPCR } \\
\text { ligand }\end{array}$ & $\begin{array}{c}\text { Ion channel } \\
\text { modulator }\end{array}$ & $\begin{array}{c}\text { Kinase } \\
\text { inhibitor }\end{array}$ & $\begin{array}{c}\text { Nuclear receptor } \\
\text { ligand }\end{array}$ & $\begin{array}{c}\text { Protease } \\
\text { inhibitor }\end{array}$ & $\begin{array}{c}\text { Enzyme } \\
\text { inhibitor }\end{array}$ \\
\hline Glabridin & 0.19 & -0.07 & 0.08 & 0.83 & 0.09 & 0.50 \\
\hline
\end{tabular}

Table 3: Calculation of Bioactivity score of best Ligands

\section{Analysis of Toxicity Predication}

The screening tests of three ligands demonstrated that they are non-mutagens and noncarcinogens, based on the data set. These compounds passed all toxicity parameters, indicating that they might be developed as future Cholinesterase inhibitors medicines to be treated Alzheimer's pathology. The in-silico toxicity profile of these compounds is shown in Table 4.

\begin{tabular}{|c|c|c|c|c|}
\hline Chemical formula & Log $\mathbf{S}$ & Mutagenicity & carcinogenicity & Irritant \\
\hline $\mathbf{C}_{\mathbf{2 0}} \mathbf{H}_{\mathbf{2 0}} \mathbf{O}_{\mathbf{4}}$ & -3.646 & None & None & None \\
\hline $\mathbf{C}_{\mathbf{2 0}} \mathbf{H}_{\mathbf{2 0}} \mathbf{O}_{\mathbf{5}}$ & -3.617 & None & None & None \\
\hline $\mathbf{C}_{\mathbf{1 5}} \mathbf{H}_{\mathbf{1 0}} \mathbf{O}_{\mathbf{7}}$ & -2.925 & None & None & None \\
\hline
\end{tabular}

Table 4: Toxicity Parameters of top Compounds 


\section{Conclusion:}

Based on in-silico studies, compound Glabridin has a good Cholinesterase inhibitory action as well as a higher binding affinity for the target protein 1EVE. This molecule has a low molecular weight, has no influence on the toxicity profile, and follows all five Lipinski criteria as well as bioactivity characteristics. This novel inhibitor (Glabridin) has the potential to be a potent therapeutic medicinal molecule for Alzheimer's disease therapy.

In the future, these potent Cholinesterase inhibitors compounds may be investigated in the wet lab and in-vivo investigations based on their ADME and Toxicity profiles.

Conflicts of Interest: The authors state that there is no chance for a conflict of interest.

\section{References:}

1) V. Zarotsky, J.J. Sramek, N.R. Cutler. (2003) Galanthamine hydrobromide: an agent for Alzheimer's disease, Am J Health Syst Pharm. 60 446-452.

2) E.M. Reiman. (2006) A 100-Year Update on Alzheimer's disease and related disorders, J Clin Psychiatry. 67 1784-1800.

3) E. Perry, M. Walker, J. Grace, R. Perry. (1999) Acetylcholine in mind a neurotransmitter correlate of consciousness? Trends. Neurosci. 22 273-280.

4) R. Wang, X.C. Tang. (2005) Neuroprotective Effects of Huperzine A, Neurosignals. 147182.

5) J. Massoulie, L. Pezzementi, S. Bon, E. Krejci, F.M. Vallette. (1993) Molecular and cellular biology of cholinesterases, Prog. Neurobiol. 41 31-91.

6) L.W. Chacho, J.A. Cerf. (1960) Histochemical localization of cholinesterase in the amphibian spinal cord and alterations following ventral root section, J. Anat. 9474-81.

7) G.B. Koelle. (1954) The histochemical localization of cholinesterases in the central nervous system of the rat, J. Comp. Anat. 100211-235.

8) Y.J. Huang, Y. Huang, H. Baldassarre, B. Wang, A. Lazaris, M. Leduc, A.S. Bilodeau, A. Bellemare, M. Cote, P. Herskovits, M. Touati, C. Turcotte, L. Valeanu, N. Lemee, H. Wilgus, I. Begin, B. Bhatia, K. Rao, N. Neveu, E. Brochu, J. Pierson, D.K. Hockley, D.M. Cerasoli, D.E. Lenz, C.N. Karatzas, S. Langermann S. (2007) Recombinant human butyrylcholinesterase from the milk of transgenic animals to protect against organophosphate poisoning, Proc. Natl. Acad. Sci. U.S.A. 104 13603-13608.

9) G.L. Wenk(2006) Neuropathologic changes in Alzheimer's disease: potential targets for treatment, J Clin Psychiatry.67 3-7.

10) L.M. Bierer, V. Haroutunian, S. Gabriel, P.J. Knott, L.S. Carlin, D.P. Purohit, D.P. Perl, J. Schmeidler, P. Kanof, K.C. Davis. (1995) Neurochemical correlates of dementia severity in Alzheimer's disease: Relative importance of the cholinergic deficits, J Neurochem. 64 749-760. 
11) C.K. Wu, L. Thal, D. Pizzo, L. Hansen, E. Masliah, C. Geula. (2005) Apoptotic signals within the basal forebrain cholinergic neurons in Alzheimer's disease, Exp Neurol. 195 484-496.

12) Joyner, P. M., and Cichewicz, R. H. (2011) Bringing Natural Products into the Fold - Exploring the Therapeutic Lead Potential of Secondary Metabolites for the Treatment of Protein-Misfolding-Related Neurodegenerative Diseases. Nat. Prod. Rep. 28, 26.

13) Molecular Graphics Laboratory, The Scripps Research Institute Available from: www.scripps.edu, graphics laboratory (MGL) tools, and AutoDock4.2, downloaded on 25 July 2019.

14) Accelrys, Available from: www.accelerys.com, Discovery studio visualizer 2.5 .5 downloaded on 22 July 2019.

15) http://www.molinspiration.com/cgi-bin/properties

16) Saha S and Acharya M. (2014) In-silico ADME-toxicity profiling, prediction of bioactivity and CNS penetrating properties of some newer resveratrol analogs. Journal of Pharma Sci-Tech; 3: 98-0. 